\title{
PENGEMBANGAN MENARA TELEKOMUNIKASI DI KABUPATEN PULANG PISAU
}

\author{
Amiany \\ Jurusan/Program Studi Arsitektur, Fakultas Teknik, Universitas Palangka Raya \\ Jln. Hendrik Timang, Palangka Raya, e-mail: amiany@arch.upr.ac.id
}

\begin{abstract}
With the growing and increasing telecommunication business activities in line with the growing needs of the community for infrastructure, the use of telecommunications and informatics facilities in Central Kalimantan Province has encouraged the development of telecommunication towers and various supporting facilities. The high demand for telecommunications and information services followed by the presence of telecommunication tower supporting facilities is faced with the problem of the location of telecommunication towers which have a negative impact on the environment, the quality of Visiual Space, and security and safety due to the irregularity of the tower location, so that for the safety and comfort of the community and to preserve the environment, it is necessary to arrange the construction of telecommunications tower infrastructure. This research essentially aims to inventory / collect data regarding the construction of telecommunications towers to maximize signals and minimize blank spots and to be more planned for the construction of new telecommunications towers in Pulang Pisau District.
\end{abstract}

Key Word: Facility, Telecommunication Tower, blank spot

\begin{abstract}
Abstrak: Dengan semakin meningkatnya dan semakin berkembangnya aktivitas bisnis telekomunikasi seiring dengan pertumbuhan kebutuhan masyarakat akan infrastruktur, penggunaan fasilitas telekomunikasi dan informatika di Provinsi Kalimantan Tengah telah mendorong pengembangan menara telekomunikasi dan berbagai fasilitas pendukung. Tingginya permintaan layanan telekomunikasi dan informasi yang diikuti dengan hadirnya fasilitas pendukung menara telekomunikasi dihadapkan pada masalah lokasi menara telekomunikasi yang berdampak negatif terhadap lingkungan, kualitas Ruang Visiual, dan keamanan dan keselamatan akibat ketidakberaturan lokasi menara, sehingga untuk keamanan dan kenyamanan masyarakat dan untuk melestarikan lingkungan, perlu mengatur pembangunan infrastruktur menara telekomunikasi. Penelitian ini pada dasarnya bertujuan untuk menginventarisasi / mengumpulkan data mengenai pembangunan menara telekomunikasi untuk memaksimalkan sinyal dan meminimalkan titik-titik kosong dan lebih direncanakan untuk pembangunan menara telekomunikasi baru di Kabupaten Pulang Pisau.
\end{abstract}

Kata Kunci: Fasilitas, Menara Telekomunikasi, tempat kosong

\section{PENDAHULUAN}

Dalam rangka penataan menara telekomunikasi, telah ditetapkan Peraturan Menteri Komunikasi dan Informatika Republik Indonesia No. 02/PER/M.KOMINFO/3/2008 tentang Pedoman Pembangunan dan Penggunaaan Menara Bersama Telekomunikasi dan Peraturan Bersama Menteri Dalam Negeri, Menteri Pekerjaan Umum, menteri Komunikasi dan Informatika, dan Kepala Badan Koordinasi Penanaman Modal, no. 3/P/2009 tentang Pedoman Pembangunan dan Penggunaan Bersama Menara Telekomunikasi. Muatan yang ada pada peraturan perundang-undangan tersebut menunjukkan bahwa lokasi pembangunan menara telekomunikasi wajib mengikuti rencana tata ruang untuk mencapai efetifitas, efesiensi dan estetika ruang

Pemasangan dan pembangunan menara telekomunikasi ini harus ditata sedemikian rupa sehingga tidak terjadi tumpang tindih jaringan dan memaksimalkan sinyal telekomunikasi sehingga meminimalisir wilayah blank spot di Kabupaten Pulang Pisau. Dalam hal ini diperlukan inventarisasi pembangunan tower tower telekomunikasi yang selanjutnya ditata untuk pembangunan tower - tower baru agar lebih maksimal jangkauan sinyal yang pada akhirnya akan semakin membuka keisolasian wilayah dan untuk meningkatkan kesejahteraan masyarakat di Kabupaten Pulang Pisau. 
Maksud kegiatan ini adalah inventarisasi/pengumpulan data mengenai pembangunan tower- tower telekomunikasi guna memaksimalkan sinyal dan meminimalisir blank spot serta agar lebih terencana untuk pembangunan menara telekomunikasi yang baru di Kabupaten Pulang Pisau. Tujuan yang ingin dicapai dalam kegiatan ini adalah tertatanya pembangunan menara telekomunikasi dengan memaksimalkan sinyal telekomunikasi untuk meminimalisir wilayah blank spot guna membuka keterisolasian daerah demi kesejahteraan rakyat Kabupaten Pulang Pisau.

\section{SEBARAN DAN CAKUPAN MENARA TELEKOMUNIKASI DI KABUPATEN PULANG PISAU}

Jumlah pemilik tower menara telekomunikasi di Kabupaten Pulang Pisau Provinsi Kalimantan Tengah terdiri dari Telkomsel, Indosat, XL, Three, dan Flexi. Telkomsel merupakan pemilik tower menara telekomunikasi terbesar yaitu 25 unit, disusul Indosat 10 unit, XL 8 unit, Three 10 unit, dan 3 Flexi. Sebaran kepemilikan di Kabupaten Pulang Pisau dapat dilihat pada Tabel 1 dan Table 2 berikut.

Tabel 1. Jumlah Menara Berdasarkan Pemilik Tower di Kabupaten Pulang Pisau

\begin{tabular}{|c|l|c|c|c|c|c|c|}
\hline \multirow{2}{*}{ No } & \multirow{2}{*}{ Kecamatan } & \multicolumn{4}{|c|}{$\begin{array}{c}\text { Jumlah Merdasarkan Pemilik } \\
\text { Tower (Unit) }\end{array}$} & \multirow{2}{*}{$\begin{array}{c}\text { Jumlah } \\
\text { (Unit) }\end{array}$} \\
\cline { 3 - 7 } & & $\mathbf{1}$ & $\mathbf{2}$ & $\mathbf{3}$ & $\mathbf{4}$ & $\mathbf{5}$ & \\
\hline \multirow{2}{*}{1} & $\begin{array}{l}\text { Kahayan } \\
\text { Kuala }\end{array}$ & 1 & 1 & 1 & - & - & 3 \\
\hline 2 & $\begin{array}{l}\text { Sebangau } \\
\text { Kuala }\end{array}$ & 1 & - & - & - & - & 1 \\
\hline 3 & Pandih Batu & 2 & 1 & 1 & - & - & 4 \\
\hline 4 & Maliku & 4 & 2 & - & - & - & 6 \\
\hline 5 & Kahayan Hilir & 6 & 3 & 1 & 4 & 2 & 16 \\
\hline 6 & Jabiren Raya & 5 & 2 & 4 & 6 & 1 & 18 \\
\hline 7 & $\begin{array}{l}\text { Kahayan } \\
\text { Tengah }\end{array}$ & 3 & 1 & 1 & - & - & 5 \\
\hline 8 & $\begin{array}{l}\text { Banama } \\
\text { Tingang }\end{array}$ & 3 & - & - & - & - & 3 \\
\hline & Total & 25 & 10 & 8 & 10 & 3 & 46 \\
\hline
\end{tabular}

Sumber : Hasil Survey Lapangan (2014)

$\begin{array}{lll}1 \text { Telkomsel } & 3 \mathrm{XL} & 5 \text { Flexi } \\ 2 \text { Indosat } & 4 \text { Three }\end{array}$

Tabel 2. Cakupan Menara Telekomunikasi di Kabupaten Pulang Pisau

\begin{tabular}{|c|l|c|c|c|}
\hline No. & Kecamatan & $\begin{array}{c}\text { Luas } \\
\text { Kecamatan } \\
(\mathrm{Km} 2)\end{array}$ & $\begin{array}{c}\text { Luas } \\
\text { Cakupan } \\
\text { Layanan } \\
(\text { Km2 })\end{array}$ & $\begin{array}{c}\text { Presentase } \\
(\%)\end{array}$ \\
\hline 1 & $\begin{array}{l}\text { Kahayan } \\
\text { Kuala }\end{array}$ & $1.155,00$ & 205,44 & 17,79 \\
\hline 2 & $\begin{array}{l}\text { Sebangau } \\
\text { Kuala }\end{array}$ & $3.801,00$ & 175,39 & 4,61 \\
\hline 3 & Pandih Batu & 535,86 & 263,13 & 49,10 \\
\hline 4 & Maliku & 413,14 & 314,07 & 76,02 \\
\hline 5 & $\begin{array}{l}\text { Kahayan } \\
\text { Hilir }\end{array}$ & 360,00 & 315,96 & 87,77 \\
\hline 6 & Jabiren Raya & $1.323,00$ & 623,03 & 47,09 \\
\hline 7 & $\begin{array}{l}\text { Kahayan } \\
\text { Tengah }\end{array}$ & 783,00 & 458,03 & 58,50 \\
\hline 8 & $\begin{array}{l}\text { Banama } \\
\text { Tingang }\end{array}$ & 626,00 & 153,82 & 24,57 \\
\hline & Jumlah & $8.997,00$ & $2.508,87$ & 27,89 \\
\hline
\end{tabular}

Sumber : Hasil Olah Data (2014)

\section{ZONA PERSEBARAN TELEKOMUNIKASI}

MENARA

Zona pesebaran menara telekomunikasi adalah wilayah yang seharusnya mendapat layanan menara telekomunikasi. Zona walayah telekomunikasi tersebut mencakup wilayah kawasan permukiman, pusat-pusat kegiatan seperti pertambangan, perkebunan, dan kegiatan lain karena adanya aktivitas manusia. Sebaran zona menara dapat dilihat pada Tabel 3.

Secara keseluruhan 8 (delapan) wilayah kecamatan di Kabupaten Pulang Pisau telah mendapat layanan menara telekomunikasi. Cakupan layanan zona menara telekomunikasi seluas 2,508.87 $\mathrm{Km} 2$ atau $27.89 \%$, yang tersebar pada 12 kecamatan.

Cakupan layanan menara telekomunikasi terbesar di kecamatan Kahayan Hilir dengan persentasi cakupan zona layanan $87.77 \%$. Sedangkan yang terkecil di kecamatan Sebangau Kuala hanya dengan persentasi cakupan zona layanan $4.61 \%$. Besarnya cakupan layanan menara pada Kecamatan Kahayan Hilir terkonsentrasi di kawasan perkotaan Kota Pulang Pisau yang merupakan Ibu Kota Kabupaten. Pada Gambar 1 peta dibawah ini akan disajikan persebaran menara telekomuniasi di Kabupaten Pulang Pisau. 
Tabel 3. Zona Persebaran Menara Telekomunikasi di Kabupaten Pulang Pisau

\begin{tabular}{|c|c|c|c|c|c|c|c|}
\hline No. & Kecamatan & $\begin{array}{l}\text { Luas Kecamatan } \\
\qquad(\mathrm{Km} 2)\end{array}$ & $\begin{array}{c}\text { Luas Cakupan } \\
\text { Zona Layanan } \\
(\mathrm{Km} 2)\end{array}$ & $\begin{array}{c}\text { Persentase } \\
\text { Cakupan Zona } \\
\text { Layanan } \\
\text { (\%) }\end{array}$ & $\begin{array}{l}\text { Luas Zona } \\
\text { Sasaran } \\
(\mathrm{Km} 2)\end{array}$ & $\begin{array}{c}\text { Luas Zona } \\
\text { Wilayah Yang } \\
\text { Belum Terlayani } \\
\text { (Km2) }\end{array}$ & $\begin{array}{c}\text { Persentase Zona } \\
\text { Yang Belum } \\
\text { Terlayani } \\
\text { (\%) }\end{array}$ \\
\hline 1 & Kahayan Kuala & $1.155,00$ & 205,44 & 17,79 & 417,81 & 531,75 & 46,04 \\
\hline 2 & Sebangau Kuala & $3.801,00$ & 175,39 & 4,61 & 727,50 & $2.898,11$ & 76,25 \\
\hline 3 & Pandih Batu & 535,86 & 263,13 & 49,10 & 107,81 & 164,92 & 30,78 \\
\hline 4 & Maliku & 413,14 & 314,07 & 76,02 & 50,12 & 48,95 & 11,85 \\
\hline 5 & Kahayan Hilir & 360,00 & 315,96 & 87,77 & - & 44,04 & 12,23 \\
\hline 6 & Jabiren Raya & $1.323,00$ & 623,03 & 47,09 & 64,17 & 635,80 & 48,06 \\
\hline 7 & Kahayan Tengah & 783,00 & 458,03 & 58,50 & 157,03 & 167,94 & 21,45 \\
\hline 8 & Banama Tingang & 626,00 & 153,82 & 24,57 & 67,39 & 404,79 & 64,66 \\
\hline & Jumlah & $8.997,00$ & $2.508,87$ & 27,89 & $1.591,83$ & $4.896,30$ & 54,42 \\
\hline
\end{tabular}

Sumber : Hasil Olah Data (2014)

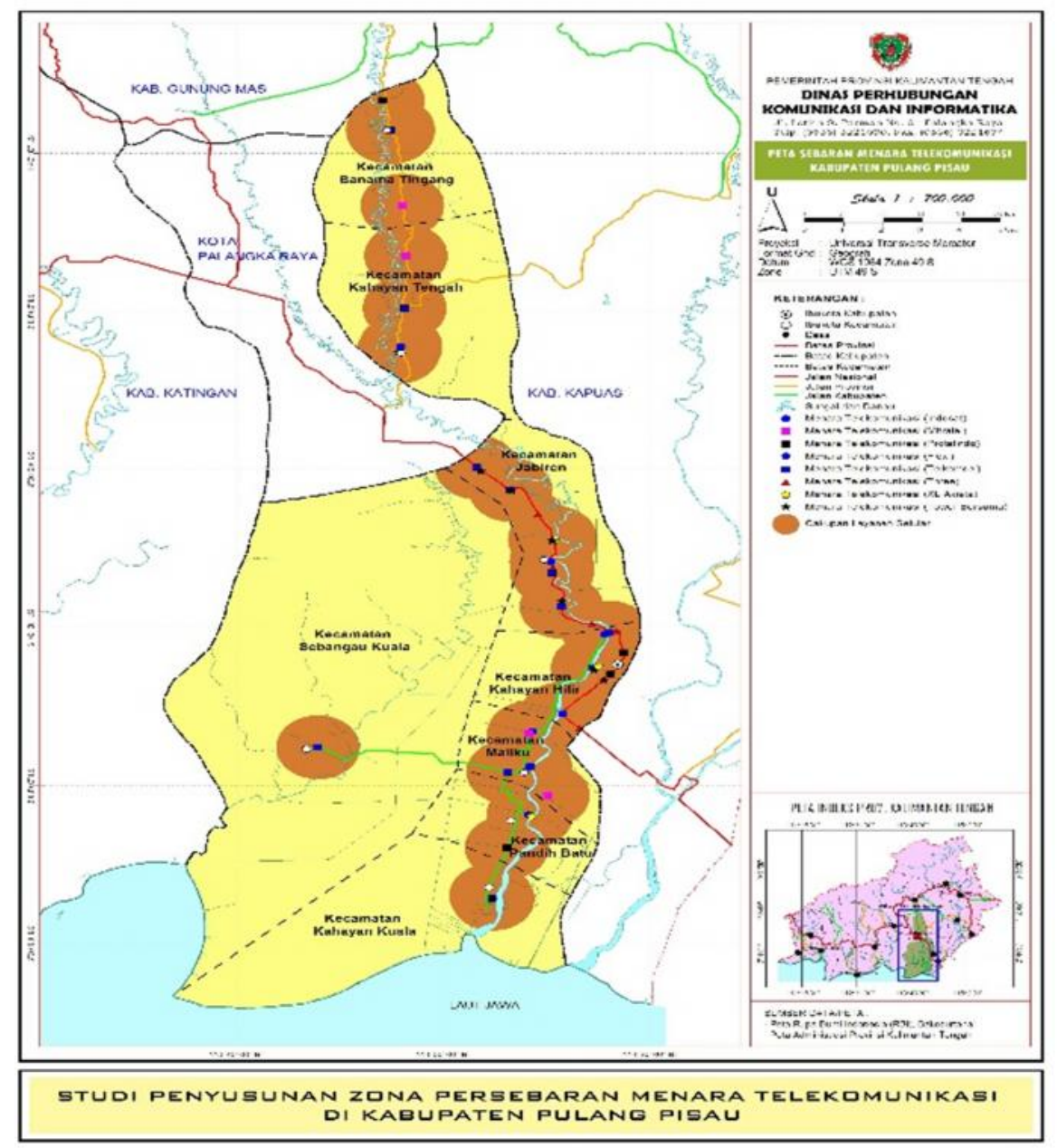

Gambar 1. Peta persebaran rencana menara telekomunikasi di Kabupaten Pulang Pisau (2014) 


\section{RENCANA PENGEMBANGAN MENARA BARU}

Berkaitan dengan pembangunan menara tersebut, pemerintah daerah harus melakukan langkah-langkah:

a. Pemerintah Daerah harus menyusun pengaturan penempatan lokasi Menara sesuai dengan ketentuan perundangundangan yang berlaku.

b. Pemerintah Daerah dalam menyusun pengaturan penempatan Menara sebagaimana yang dimaksud harus mempertimbangkan aspek - aspek teknis dalam penyelenggaraan telekomunikasi dan prinsip-prinsip penggunaan Menara Bersama.

c. Pengaturan penempatan lokasi Menara sebagaimana dimaksud harus memperhatikan prinsip-prinsip tata kelola pemerintahan yang baik, dilakukan dengan mekanisme yang transparan dan dengan melibatkan peran masyarakat dalam menentukan kebijakan untuk penataan ruang yang efisien dan efektif demi kepentingan umum.

Ada beberapa kawasan kecamatan di Kabupaten Pulang Pisau masih belum terjangkau oleh menara telekomunkasi (blank spot) sehingga dibutuhkan bangunan baru, namun disarankan untuk menggunakan tower bersama. Perlu adanya kerjasama pemerintah daerah terutama dalam hal ini adalah langsung di bawah Kepala Daerah guna lebih bisa berjalan maksimal dan efisien dalam hal pemerataaan pembangunan menara kedepannya. Pemerintah Daerah harus memperhatikan ketentuan hukum tentang larangan praktek monopoli dan persaingan usaha tidak sehat dalam pembangunan Menara pada wilayahnya.

Pemerintah dan pemerintah daerah sesuai kewenangannya dapat menetapkan lebih lanjut kriteria teknis penetapan zona bebas menara dan sub zona menara bebas visual. Kewenangan dimaksud dilaksanakan oleh tim yang ditunjuk oleh instansi terkait. Tim tersebut melibatkan instansi terkait, kalangan akademisi, asosiasi profesi, dan pemangku kepentingan lain sesuai kebutuhan.

Berdasarkan hasil olah data, rencana pengguna telekomunikasi di Pulang Pisau mencapai 7.678 jiwa yang tersebar di beberapa kecamatan yang meliputi : kecamatan Banama Tingang, kecamatan Sebangau dan kecacatan Kahayan Kuala. Pada tabel 4 dan 5 dan Gambar 2 peta berikut ini akan disajikan persebaran rencana menara telekomuniasi di Kabupaten Pulang Pisau untuk memenuhi kebutuhan akan jaringan komunikasi di wilayah yang masih blank spot (tidak ada sinyal komunikasi).

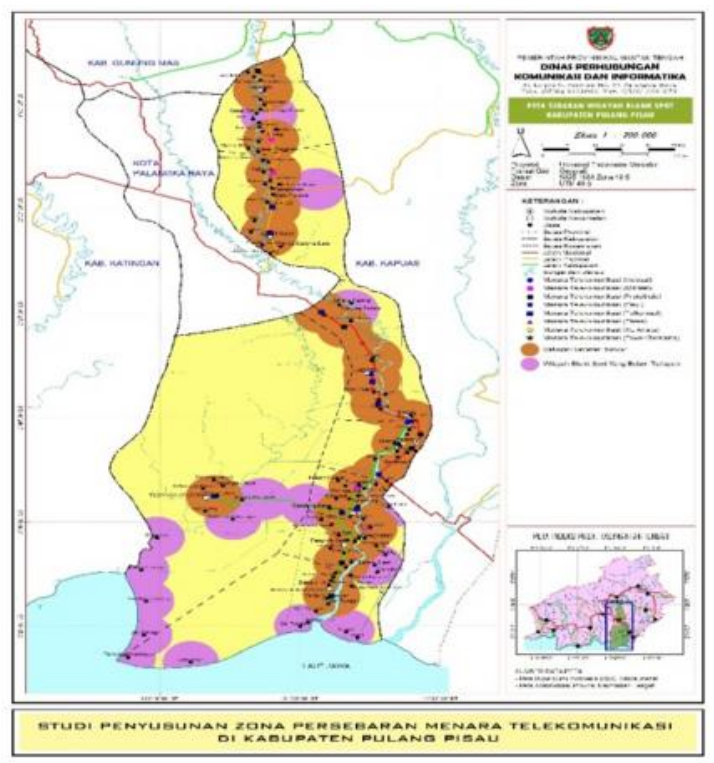

Gambar 2. Peta Rencana Menara Telekomuniasi Di Kabupaten Pulang Pisau Yang Masih Blank Spot (tidak ada sinyal komunikasi) 2014 
Tabel 4. Rencana Menara Baru di Kabupaten Pulang Pisau

\begin{tabular}{|c|c|c|c|c|c|c|}
\hline $\begin{array}{l}\text { No. } \\
\text { Tower }\end{array}$ & Letak Menara & Kecamatan & Cakupan Layanan & Ketinggian & Lintang Selatan & Bujur Timur \\
\hline 01 & Tangkahen & Banama Tingang & Tangkahen, Pandawei & 72 Meter & $01^{0} 3338,0^{\prime \prime}$ & $113^{0} 53^{\prime} 43,0^{\prime \prime}$ \\
\hline 02 & Ramang & Banama Tingang & Ramang, Tambak, Kasali Baru & 72 Meter & $01^{0} 42^{\prime} 01,0^{\prime \prime}$ & $113^{0} 56^{\prime} 44,0^{\circ}$ \\
\hline 03 & Tuwung & Kahayan Tengah & Tuwung & 72 Meter & $02^{0} 04^{\prime} 21,0^{\prime \prime}$ & $113^{0} 54^{\prime 1} 13,0^{\prime \prime}$ \\
\hline 04 & Penda Barania & Kahayan Tengah & Penda Barania & 72 Meter & $02^{0} 06^{\prime} 57,0^{\prime \prime}$ & $113^{0} 55^{\prime} 47,0^{\prime \prime}$ \\
\hline 05 & Tanjung Sangalang & Kahayan Tengah & Tanjung Sangalang & 72 Meter & $02^{0} 0759,0^{\prime \prime}$ & $113^{0} 57^{\prime} 42,0^{\prime \prime}$ \\
\hline 06 & Paduran Sebangau & Sebangau & Paduran Sebangau & 72 Meter & $02^{0} 5932,0^{\prime \prime}$ & $113^{0} 5138,0^{\prime \prime}$ \\
\hline 07 & Sei Hambawang & Sebangau & Sei Hambawang & 72 Meter & $03^{0} 15^{\prime 2} 20,0^{\prime \prime}$ & $113^{0} 3859,0^{\prime \prime}$ \\
\hline 08 & Sei Bakau & Sebangau & Sei Bakau & 72 Meter & $03^{0} 2157,0^{\prime \prime}$ & $113^{0} 3835,0^{\prime \prime}$ \\
\hline 09 & Cemantan & Kahayan Kuala & Cemantan & 72 Meter & $03^{0} 27^{\prime} 05,0^{\prime \prime}$ & $113^{0} 45^{\prime} 13,0^{\prime \prime}$ \\
\hline 10 & Sei Pudak & Kahayan Kuala & Sei Pudak, Sei Barunai, Sei Pasanan & 72 Meter & $03^{0} 20^{\prime} 06,0^{\prime \prime}$ & $114^{0} 01^{\prime 24,0^{\prime \prime}}$ \\
\hline 11 & Kiapak & Kahayan Kuala & Kiapak & 72 Meter & $03^{0} 2721,0^{\prime \prime}$ & $114^{0} 07^{\prime} 42,0^{\prime \prime}$ \\
\hline
\end{tabular}

Sumber: Hasil Olah Data (2014)

Tabel 5. Perkiraan Banyaknya Pengguna Telekomunikasi di Kabupaten Pulang Pisau

\begin{tabular}{|c|c|c|c|c|c|}
\hline $\begin{array}{l}\text { No. } \\
\text { Tower }\end{array}$ & Kecamatan & Letak Menara & Cakupan Layanan & Jumlah Penduduk & $\begin{array}{l}\text { Perkiraan } \\
\text { Pengguna }\end{array}$ \\
\hline 01 & Banama Tingang & Tangkahen & $\begin{array}{l}\text { Tangkahen } \\
\text { Pandawei }\end{array}$ & $\begin{array}{c}1.258 \\
276\end{array}$ & $\begin{array}{l}755 \\
166\end{array}$ \\
\hline 02 & Banama Tingang & Ramang & $\begin{array}{c}\text { Ramang } \\
\text { Tambak } \\
\text { Kasali Baru }\end{array}$ & $\begin{array}{l}493 \\
321 \\
250\end{array}$ & $\begin{array}{l}296 \\
193 \\
150\end{array}$ \\
\hline 03 & Kahayan Tengah & Tuwung & Tuwung & 514 & 308 \\
\hline 04 & Kahavan Tengah & Penda Barania & Penda Barania & 152 & 91 \\
\hline 05 & Kahavan Tengah & Tanịung Sangalang & Tanịung Sangalang & 351 & 211 \\
\hline 06 & Sebangau & Paduran Sebangau & Paduran Sebangau & 1.885 & 1.131 \\
\hline 07 & Sebangau & Sei Hambawang & Sei Hambawang & 1.015 & 609 \\
\hline 08 & Sebangau & Sei Bakau & Sei Bakau & 949 & 569 \\
\hline 09 & Kahayan Kuala & Cemantan & Cemantan & 1.189 & 713 \\
\hline 10 & Kahayan Kuala & Sei Pudak & $\begin{array}{l}\text { Sei Pudak } \\
\text { Sei Barunai } \\
\text { Se Pasanan }\end{array}$ & $\begin{array}{c}2.850 \\
902 \\
2.081\end{array}$ & $\begin{array}{c}1.710 \\
541 \\
1.249\end{array}$ \\
\hline 11 & Kahayan Kuala & Kiapak & Kiapak & 861 & 517 \\
\hline
\end{tabular}

Sumber : Hasil Olah Data (2014) 


\section{KESIMPULAN}

Ada beberapa kawasan kecamatan di Kabupaten Pulang Pisau masih belum terjangkau oleh menara telekomunkasi (blank spot) sehingga dibutuhkan bangunan baru, namun disarankan untuk menggunakan tower bersama.

Perlu adanya kerjasama pemerintah daerah terutama dalam hal ini adalah langsung di bawah Kepala Daerah guna lebih bisa berjalan maksimal dan efisien dalam hal pemerataaan pembangunan menara kedepannya. Pemerintah Daerah harus memperhatikan ketentuan hukum tentang larangan praktek monopoli dan persaingan usaha tidak sehat dalam pembangunan Menara pada wilayahnya.

Pemerintah dan pemerintah daerah sesuai kewenangannya dapat menetapkan lebih lanjut kriteria teknis penetapan zona bebas menara dan sub zona menara bebas visual. Kewenangan dimaksud dilaksanakan oleh tim yang ditunjuk oleh instansi terkait. Tim tersebut melibatkan instansi terkait, kalangan akademisi, asosiasi profesi, dan pemangku kepentingan lain sesuai.

\section{DAFTAR PUSTAKA}

Amiany (2016). Peran Tata Ruang dan Pertanahan Dalam Perijinan dan Penyusunan RDTR, Kegiatan Sosialisasi Integrasi Penyelenggaraan Penataan Ruang dan Pertanahan, PU Provinsi Kalteng, Palangka Raya.

Bobi Setiawan (2013). Overview dan Isu-isu UU No.26 Tahun 2007, Pelatihan Perencanaan Tata Ruang, UGM Yogyakarta.

BPN Provinsi Kalteng (2016). Penyusunan RDTRK Berbasis Bidang Tanah, Kegiatan Sosialisasi Integrasi Penyelenggaraan Penataan Ruang dan Pertanahan, PU Provinsi Kalteng, Palangka Raya.

DEPKOINFO Provinsi Kalimantan Tengah, (2014). Studi Penyusunan Zona Persebaran Menara Telekomunikasi di Kabupaten. Pulang Pisau Tahun 2014, Palangka Raya.

Muta'ali, Lufti (2013). Penataan Ruang Wilayah dan Kota (tinjauan NormatifTeknis), Fakultas Geografi UGM, Yogyakarta, 2013.
Peraturan Menteri Komunikasi dan Informatika RI No. 02/PER/M.KOMINFO/3/2008.

Permen PU No. 20 Tahun 2011, Kedudukan RDTR Kabupaten/Kota dalam Sistem Penataan Ruang dan Sistem Perencanaan Pembangunan NasionalPU Kabupaten Pulang Pisau (2013). Rencana Detail Tata Ruang Wilayah Kabupaten Pulang Pisau, 2013.

Pratama, M Arszandi (2015). Menata Kota melalui Rencana Detail Tata Ruang (RDTR), Andi, Yogyakarta

PU Kabupaten Pulang Pisau (2013). Rencana Detail Tata Ruang Ibukota Kecamatan Jabiren Raya Kabupaten Pulang Pisau, 2013.

Surat Edaran Direktorat Jenderal Penataan Ruang Kementerian Pekerjaan Umum No. 06/SE/Dr/2011. 